\title{
PKM Blended Learning dengan Google Classroom for Education bagi Guru SMA Sederajat di Kecamatan Tambusai Provinsi Riau
}

\author{
Budi Yanto \\ Fakultas Ilmu Komputer, Universitas Pasir Pengaraian \\ budiyantost@gmail.com \\ Agung Setiawan \\ Fakultas Ilmu Komputer, Universitas Pasir Pengaraian \\ agungsetiawan74@gmail.com \\ Rijalul Husni \\ Fakultas Pendidikan dan Ilmu Keguruan Universitas Pasir Pengaraian \\ rijalul_husni@gmail.com
}

Naskah diterima: 10 Januari 2020| Naskah disetujui: 8 Februari 2020

\begin{abstract}
In accordance with its development, especially in the era of disruption 4.0 that future teachers should be able to present the appropriate module that meets passion of students, in the era of the development of emerging technology, the modules used in the study are not always use the conventional modules such as paper-based modules. Rather, the future teacher must be able to present course material in the form of modules that can be accessed online by students. Teachers must be able to present the joyful and innovative learning, i.e. learning that blends hands on and mind on, problem-based leraning and project based learning The goal is to create an active learning, creative and fun. Google Classroom for Education is one of the features of the free Google product that can be used as a medium of blended learning. With a variety of features it has, Google Classroom can be used to demonstrate or visualize concept of lessons with no face to face needed. Community Partnership program is one of the mentoring, coaching, and training activities to high school teachers in Tambusai in Rokan Hulu, Riau. The results of this activity is expected to build teachers who are capable of designing learning program by utilizing Google Classroom for Education as a medium of learning that is blended and occurs in digital paperless classroom.

Keywords: blended learning, Google Classroom, paperless
\end{abstract}

\begin{abstract}
Abstrak
Sesuai dengan perkembangannya terutama pada era disrupsi 4.0 yaitu guru masa depan harus mampu menyajikan modul sesuai minat siswa, di era perkembangan teknologi yang semakin berkembang, modul yang digunakan dalam pembelajaran tidak selalu menggunakan modul konvensional seperti modul berbasis paper. Melainkan guru masa depan pun harus mampu menyajikan materi pelajaran dalam bentuk modul yang bisa diakses secara daring oleh para siswa. Guru masa depan harus mampu menyajikan pembelajaran yang menyenangkan dan inovatif, yakni pembelajaran yang memadukan hands on and mind on, problem based learning dan project based learning. Tujuannya adalah untuk menciptakan pembelajaran yang aktif, kreatif dan menyenangkan. Google Classroom for Education merupakan salah satu fitur dari produk Google
\end{abstract}


yang dapat dimanfaatkan sebagai media blended learning. Dengan berbagai fitur yang dimilikinya, Google Classroom dapat digunakan untuk mendemontrasikan atau memvisualisasikan konsepkonsep pelajaran secara online tanpa mesti tatap muka. Kegiatan Pengabdian Kemitraan Masyarakat ini merupakan salah satu kegiatan pendampingan, pembimbingan, dan pelatihan kepada Guru SMA di Kecamatan Tambusai di kabupaten Rokan Hulu, Riau. Hasil dari kegiatan pengabdian ini diharapkan dapat melahirkan guru yang mampu merancang pembelajaran dengan memanfaatkan Google Classroom for Education sebagai media pembelajaran blended learning dalam kelas digital tanpa kertas (paperless).

Kata kunci: pembelajaran campuran, Google Classroom, pembelajaran tanpa kertas

\section{Pendahuluan}

Google Classroom (Ruang Kelas Google) adalah suatu serambi yang diperuntukkan bagi ruang lingkup pendidikan yang dimaksudkan untuk menemukan jalan keluar atas kesulitan dalam melaksanakan pembelajaran secara daring. Perangkat lunak ini telah diperkenalkan sebagai keistimewaan Google Apps for Education yang secara resmi dibagikan pada khalayak sejak 12 Agustus 2014. Google sudah melakukan pemberitahuan mengenai antarmuka pemrograman aplikasi dari sebuah ruang kelas dan sebuah tombol berbagi untuk situs web sehingga pihak kepengelolaan sekolah beserta para pengembang diperkenankan supaya melakukan penerapan lebih lanjut terhadap Google Classroom.

Pembelajaran berbasis teknologi informasi yang terangkum dalam Learning Managemen System (LMS) memang akan memberikan pengalaman terbaik bagi guru dan siswa saat melakukan kegiatan belajar mengajar (KBM). Model pembelajaran seperti ini merupakan salah satu model pembelajaran inovatif berbasis e-learning yang tentunya mendukung adanya efisiensi waktu maupun kampanye paperless learning (pembelajaran tanpa kertas). Google Classroom bisa didapatkan secara gratis dengan terlebih dahulu mendaftarkan diri pada akun Google Application for Education. Kita dapat mendaftarkan diri secara gratis untuk dapatkan Produk Google. Salah satunya adalah Google Classroom, fasilitas e-mail dengan domain sendiri, Google Drive, dan lainlain. Akun Google Apps for Education ini sangat bermanfaat untuk pembelajaran secara online, dapat diperoleh secara gratis serta dapat digunakan untuk perangkat apa pun. Salah satu kecanggihan aplikasi ini adalah dapat digunakan secara bersama-sama dalam kelompok secara kolaboratif (Asnawi 2018).

Sebagaimana jamak diketahui, dalam sistem pembelajaran berbasis teknologi informasi terutama pembelajaran online, terdapat istilah LMS (Learning Management System). Sebuah sistem untuk mengelola proses pembelajaran, yang berisi sistem terintegrasi antara model, materi, media hingga guru dan siswa yang tentunya dikembangkan terlebih dulu oleh pihak pengelola (guru dan/atau tim pendukung). Banyak LMS yang dikembangkan oleh para developer software, seperti Moodle, Edmodo, maupun website-website LMS seperti Quipperschool, Kelas, dan sebagainya. Tak terkecuali, perusahaan raksasa internet, Google juga memiliki LMS gratis yakni Google Classroom (Hakim. 2016).

Salah satu teknologi pembelajaran e-learning yang cukup terkenal dan bahkan banyak digunakan oleh institusi pendidikan besar di Indonesia adalah menggunakan Moodle, sebuah Content Management System open source yang bebas digunakan siapapun dengan bebas dan gratis. 
Akan tetapi, teknologi ini masih rentan dikarenakan saat ini banyak lembaga pendidikan yang belum memiliki keamanan web hosting yang cukup memadai terkait implementasi Moodle ini. Bahkan, celah-celah terkait keamanan (security bug) seringkali muncul ketika banyak pengguna register atau mendaftar serta bebas keluar masuk melakukan upload file yang berpotensi merusak sistem di dalam website kampus atau sekolah itu sendiri. Selain itu, masalah server down karena over capacity juga kerap mengganggu model e-learning ini, di mana sebagian besar institusi belum memiliki VPS (Virtual Private Server) atau Dedicated Server sehingga ketika akses materi elearning secara bersamaan 100 orang atau lebih misalnya, maka server akan putus (disconnected) dan website tidak bisa diakses (Pradana 2017).

Google Classroom merupakan alternatif yang bisa digunakan untuk memaksimalkan kegiatan belajar mengajar berbasis e-learning. Penggunaan Google Classroom sangat user friendly sehingga mudah digunakan, serta diimplementasikan di institusi pendidikan. Secara umum fitur yang ada pada Google Classroom adalah kelas e-learning, memberikan pengumuman, memberikan tugas, memberikan nilai, merapikan dokumen di Google Drive ketika file dari siswa/mahasiswa diupload ke dalam Google Classroom, membuat survei, membuat pertanyaan, dan sebagainya. Fitur tersebut sebenarnya bisa dikombinasikan lebih hebat lagi dengan penggunaan media yang masih terintegrasi dengan produk google lainnya, seperti Google Drive (online storage/tempat penyimpanan file secara online), Youtube (upload video), Google Form (membuat form quiz, survei, soal, dan sebagainya), Google Docs, Google Spreadsheet, dan sebagainya (Gunawan, 2018).

Berdasarkan fitur-fitur tersebut, rasanya tidak dapat dipungkiri bahwa Google Classroom dapat menjadi alternatif baru dan sangat berguna ketika suatu institusi pendidikan ingin mengembangkan kegiatan belajar di mana saja dan kapanpun. Masalah terkait kekhawatiran adanya website yang dibajak, atau server down sepertinya tidak berlaku di Google Classroom, karena seperti lazim diketahui bahwa Google memiliki keamanan atau computer security terbaik saat ini sehingga sangat kecil kemungkinan terjadi masalah-masalah tersebut. Selain itu, Google juga memberikan Analytics terhadap mekanisme e-learning yang terjadi di suatu institusi, admin atau operator dapat melihat dengan jelas berapa penggunaan atau sources yang telah digunakan dan sedang berlangsung (Wicaksono, 2017).

\section{Keunggulan Google Classroom untuk Pembelajaran Campuran}

Pembelajaran berbasis teknologi informasi yang terangkum dalam Learning Management System (LMS), akan memberikan pengalaman terbaik bagi guru dan siswa saat melakukan kegiatan belajar mengajar (KBM). Model pembelajaran seperti ini merupakan salah satu model pembelajaran inovatif berbasis e-learning. Tentunya mendukung adanya efisiensi waktu maupun kampanye paperless.

Google Classroom bisa didapatkan secara gratis dengan terlebih dahulu mendaftarkan diri pada akun Google Application for Education. Anda dapat mendaftarkan diri secara gratis untuk mendapatkan produk google. Salah satunya adalah Google Classroom, fasilitas e-mail dengan domain sendiri, Google Drive, dan lain-lain. Akun Google Apps for Education ini sangat bermanfaat untuk pembelajaran secara online, dapat diperoleh secara gratis serta dapat digunakan untuk perangkat apa pun. Salah satu kecanggihan aplikasi ini adalah dapat digunakan secara bersama-sama dalam kelompok secara kolaboratif. 
Ada beberapa keuntungan yang kita dapatkan dari cara kerja Google Classroom dalam pemanfaatannya sebagai Learning Management System (LMS), yakni:

1. Proses setting yang cepat dan nyaman

Proses instalasi Google Classroom sangat mudah asalkan terhubung koneksi dengan internet dan memiliki akun Gmail pribadi. Aplikasi ini juga bisa berjalan di Smartphone Android yang proses set up nya dengan membuka Play Store dan mencari aplikasi Google Classroom kemudian install dan langsung bisa dipakai dan diakses.

Proses set up pada Google Classroom sangat cepat dan nyaman jika dibandingkan harus menginstall LMS lokal atau mendaftarkan ke provider LMS. Guru tinggal mengakses aplikasi Google Classroom serta bisa memulai membagikan tugas-tugas dan bahan ajar. Guru dapat melakukan ini dengan menambahkan daftar siswa atau berbagi kode unik yang memungkinkan akses ke kelas pada Google Classroom. Google Classroom lebih sederhana dan mudah untuk digunakan, sehingga ideal bagi seorang guru meskipun dengan tingkat pengalaman e-learning yang beragam.

2. Hemat waktu

Guru bisa menyimpan file tugas yang akan dibuat untuk pertemuan berikutnya dan bisa dimunculkan sesuai dengan kalender jadwal yang dibuat. Siswa dapat mengerjakan di rumah dan di mana saja tanpa mesti mengerjakan di sekolah, serta menghemat pemakaian kertas.

3. Meningkatkan kerjasama dan komunikasi

Memberikan ruang tanpa batas untuk komunikasi, melalui private ataupun public comment. Dengan medium ini, komunikasi tetap berjalan tanpa mesti berjumpa, melalui fasilitas komentar dan pemberian tugas.

4. Penyimpanan data terpusat

Proses penyimpanan ini tersimpan dalam cloud computing yaitu google drive, yang aman dan bisa diakses, karena tersimpan dalam bentuk arsip.

5. Berbagi sumber daya yang cepat

Melalui fitur link apa saja bisa berbagai sumber dan bisa dicari di mesin pencari Google, berbagi video tutorial, dan bisa mengedit bersama-sama dengan fasilitas berbagi data.

Blended learning berarti gabungan antara sistem pembelajaran tatap muka (face to face) dengan pembelajaran e-learning yang dapat digunakan oleh siapa saja (everyone), di mana saja (everywhere), kapan saja (anytime). Istilah blended learning mengandung arti percampuran atau kombinasi pembelajaran atau perpaduan dari unsur-unsur pembelajaran tatap muka langsung dan online secara harmonis dan padu yang ideal (Heinze \& Procter, 2006).

Pelaksanaan Pengabdian kepada Masyarakat (PkM) dalam model pembelajaran Google Classroom untuk guru ini dalam rangka untuk mendukung upaya pelaksanaan pembelajaran yang kreatif dan menyenangkan serta membantu memvisualisasikan konsep-konsep blended learning, kepada mitra berupa pelatihan pembelajaran dan bimbingan menggunakan Google Classroom for Education. Secara detail, PkM yang diberikan adalah: 
1. Memberikan pelatihan dan bimbingan atau pendampingan kelas tanpa kertas menggunakan google classroom for education.

2. Memberikan pelatihan dan pendampingan proses set up dan settingan serta pendaftaran menggunakan Google Classroom for Education. Meningkatan kompetensi guru dalam pembelajaran menggunakan Google Classroom for Education.

\section{Metode Pelaksanaan}

Program PkM ini dilaksanakan untuk Guru SMA/SMK sederajat di Kecamatan Tambusai, Kabupaten Rokan Hulu, Provinsi Riau. Dengan kegiatan ini, diharapkan guru dapat melaksanakan pembelajaran yang kreatif dan menyenangkan serta membantu memvisualisasikan pembelajaran google classroom for education. Kepada mitra akan diberikan pelatihan pembelajaran dengan menggunakan google classroom for education, yang di dalamnya mencakup pula pembelajaran untuk siswa SMA. Selain itu dilakukan pendampingan kepada mitra, agar upaya melaksanakan pembelajaran yang aktif, kreatif, dan menyenangkan dapat terwujud dan berjalan dengan baik.

Pada praktiknya, kegiatan ini dilaksanakan dengan cara pendekatan partisipatif aktif secara berkelanjutan antara tim pengusul dengan mitra, sebagai pengendali program Kemitraan Masyarakat berperan aktif melakukan pendampingan dan pembinaan secara berkala kepada mitra.

\section{Program Kerja}

Dalam tahap persiapan, koordinasi pelaksanaan program dijalankan selama delapan bulan antara tim pengusul dan mitra. Pada tahap ini akan dilakukan persiapan-persiapan yang berhubungan dengan pelaksanaan program, sarana laboratorium komputer atau laptop pribadi dan peralatan dan bahan untuk pelatihan penggunaan google classroom for education.

Tahap berikutnya adalah tahap pelaksanaan, di mana pelaksanaan program sesuai dengan kesepakatan bersama antara tim pengusul, Guru SMA/SMK sederajat di Kecamatan Tambusai, Kabupaten Rokan Hulu, yaitu berupa penyuluhan/pelatihan/workshop antara lain :

1. Pelatihan penggunaan google classroom for education sebagai media dalam pembelajaran paperless (kelas digital/kelas tanpa kertas). Pelatihan ketrampilan ini meliputi pengetahuan dasar tentang google classroom for education, pemilihan materi pokok pembelajaran yang dapat memanfaatkan google classroom for education, serta merancang pembelajaran yang memanfaatkan google classroom for education. Dengan pelatihan ini diharapkan terjadi peningkatan kompetensi guru Guru SMA/SMK sederajat di Kecamatan Tambusai, Kabupaten Rokan Hulu.

2. Pendampingan kepada para peserta pelatihan, dalam rangka pemahaman dan aplikasi pengetahuan serta ketrampilan pembelajaran menggunakan google classroom for education. Sasarannya agar guru mampu merancang pembelajaran yang aktif, kreatif, dan menyenangkan dengan memanfaatkan google classroom for education (mulai dari perencanaan, proses pemilihan materi, dan penggunaan google classroom for education dalam pembelajaran di kelas.

3. Monitoring diperlukan juga dalam pelaksanaan kegiatan melalui motivasi pada para guru yang sudah dapat menggunakan google classroom for education untuk pembelajaran paperless (kelas 
digital, kelas tanpa kertas) di kelas sehingga bisa konsisten dan tetap bersemangat untuk terus mengembangkan pembelajaran aktif, kreatif, dan menyenangkan.

Dalam praktiknya, pelatihan google classroom for education ini memiliki tujuan untuk menjawab permasalahan mitra secara keseluruhan, mulai dari pengenalan hingga praktek pembelajaran menggunakan google classroom for education. Dengan demikian, dosen yang tergabung dalam tim bertanggung jawab untuk melatih peserta menggunakan google classroom for education hingga pendampingan pembelajaran dengan google classroom for education sesuai bidang keahlian masing-masing.

\section{Analisa dan Hasil}

PkM dalam bentuk Program Kemitraan Masyarakat yang dilaksanakan di SMAN 1 Tambusai di Kecamatan Tambusai Kabupaten Rokan Hulu ini menghasilkan beberapa kegiatan sebagai berikut:

1. Terjalinnya kerjasama dengan SMAN 1, SMAN 2, dan SMAN 3, Tambusai dalam peningkatan kompetensi guru pada penggunakan teknologi informasi dengan memanfaatkan google classroom for education untuk media blended learning dalam proses belajar mengajar online.

2. Terlaksananya pelatihan dan bimbingan dengan baik dan penuh antusias peserta dalam proses penerapan blended learning google classroom for education.

3. Meningkatnya kompetensi peserta yaitu guru-guru SMA di Kecamatan Tambusai dalam proses penerapan google classroom for education sebagai media pembelajaran online.
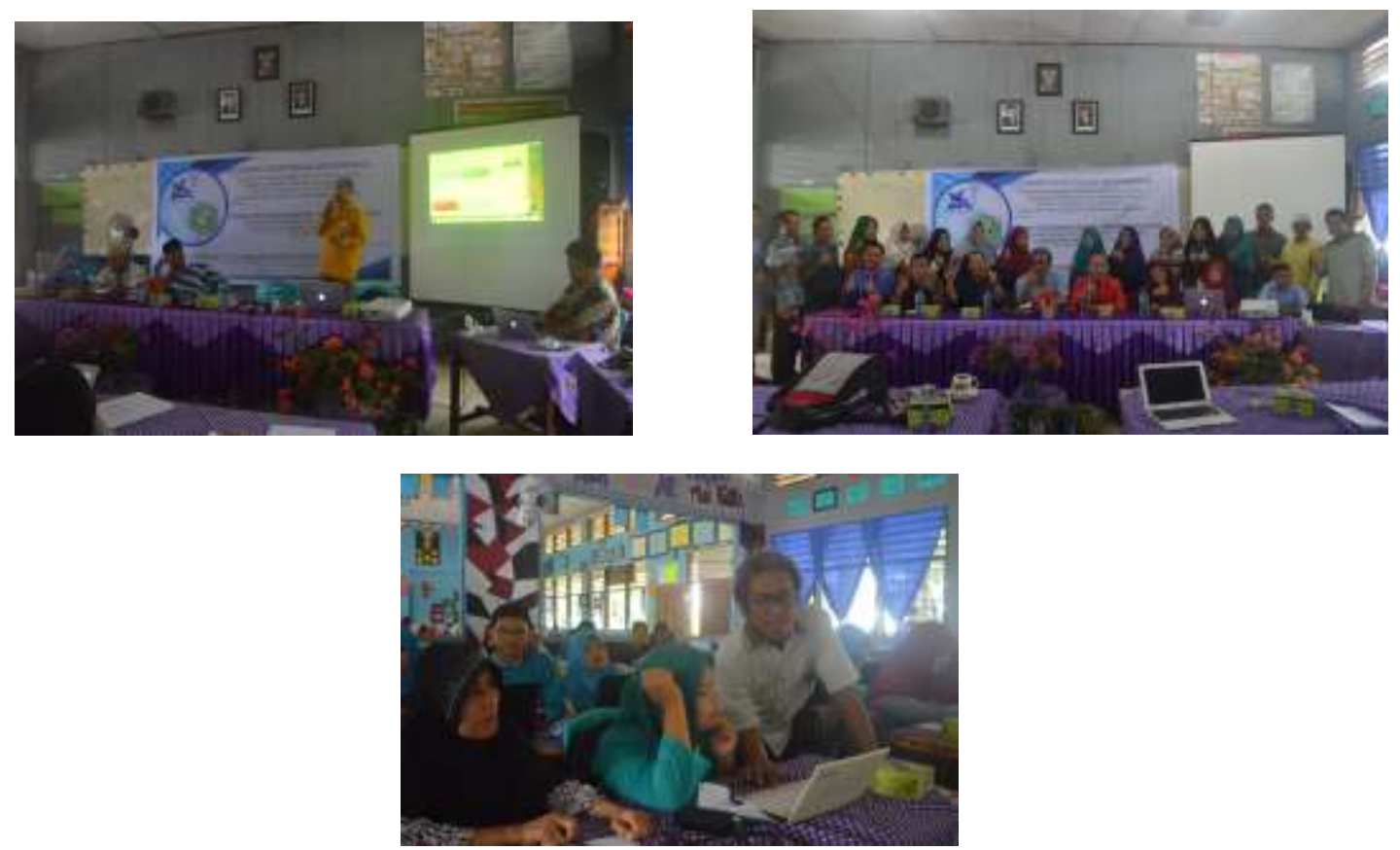

Gambar 1. Suasana pelatihan 


\section{Hasil Formulir Evaluasi Awal}

Sebelum diadakannya pelatihan Google Classroom, untuk langkah awal dilaksanakan evaluasi penilaian pemahaman dengan diberikannya kuesioner sebagai berikut terhadap 75 peserta pelatihan.

Tabel 1 Formulir Evaluasi Awal

\begin{tabular}{|c|c|c|c|c|c|c|c|c|}
\hline \multirow[t]{2}{*}{ No } & \multirow[t]{2}{*}{ Pertanyaan } & \multicolumn{3}{|c|}{ Skala } & \multicolumn{4}{|c|}{ Persentase } \\
\hline & & $\mathbf{1}$ & 2 & \begin{tabular}{l|l}
3 & 4
\end{tabular} & 1 & 2 & 3 & 4 \\
\hline 1. & $\begin{array}{l}\text { Apakah Bapak/Ibu Guru Mengetahui secara } \\
\text { jelas informasi mengenai istilah Blended } \\
\text { learning? }\end{array}$ & 0 & 0 & \begin{tabular}{l|l}
0 & 75
\end{tabular} & $0 \%$ & $0 \%$ & $100 \%$ & $\overline{0 \%}$ \\
\hline 2. & Apakah sudah mempunyai akun Gmail? & 4 & 0 & \begin{tabular}{l|ll}
0 & 71
\end{tabular} & $5,3 \%$ & $0 \%$ & $94,6 \%$ & $0 \%$ \\
\hline 3. & $\begin{array}{l}\text { Apakah Bapak/Ibu Guru mengetahui adanya } \\
\text { Blended Learning secara gratis? }\end{array}$ & 75 & 0 & $0 \mid 0$ & $100 \%$ & $0 \%$ & $0 \%$ & $0 \%$ \\
\hline 4. & $\begin{array}{l}\text { Apakah Bapak/Ibu Guru pernah menggunakan } \\
\text { situs online sebagai media pembelajaran }\end{array}$ & 60 & 0 & \begin{tabular}{l|l}
0 & 15
\end{tabular} & $80 \%$ & $0 \%$ & $20 \%$ & $0 \%$ \\
\hline 5. & $\begin{array}{l}\text { Apakah Bapak/Ibu Guru mengetahui adanya } \\
\text { Google Classroom sebagai media } \\
\text { pembelajaran gratis online? }\end{array}$ & 15 & 0 & \begin{tabular}{l|l}
0 & 60
\end{tabular} & $20 \%$ & $0 \%$ & $80 \%$ & $0 \%$ \\
\hline 6. & $\begin{array}{l}\text { Apakah Bapak/Ibu Guru memahami dan } \\
\text { pernah menggunakan Google Classroom? }\end{array}$ & 75 & 0 & \begin{tabular}{l|l}
0 & 0
\end{tabular} & $100 \%$ & $0 \%$ & $0 \%$ & $0 \%$ \\
\hline 7. & $\begin{array}{l}\text { Tidak keberatankah Apakah Bapak/lbu Guru } \\
\text { memakai dan menggunakan Google Classroom } \\
\text { sebagai media alternatif pengembangan } \\
\text { pembelajaran di sekolah? }\end{array}$ & 10 & 0 & $0 \mid 65$ & $13,3 \%$ & $0 \%$ & $86,7 \%$ & $0 \%$ \\
\hline \multicolumn{5}{|c|}{ Rata-rata } & $45,7 \%$ & $0 \%$ & $54,3 \%$ & $0 \%$ \\
\hline
\end{tabular}

Formulir Evaluasi Awal di atas berisi tentang pertanyaan yang digunakan untuk mengetahui sejauh mana pemahaman peserta tentang E-Learning dan Google Classroom, dengan menyertakan hasil peserta dari setiap pertanyaan dari 75 peserta yang mengisi Formulir Evaluasi Awal

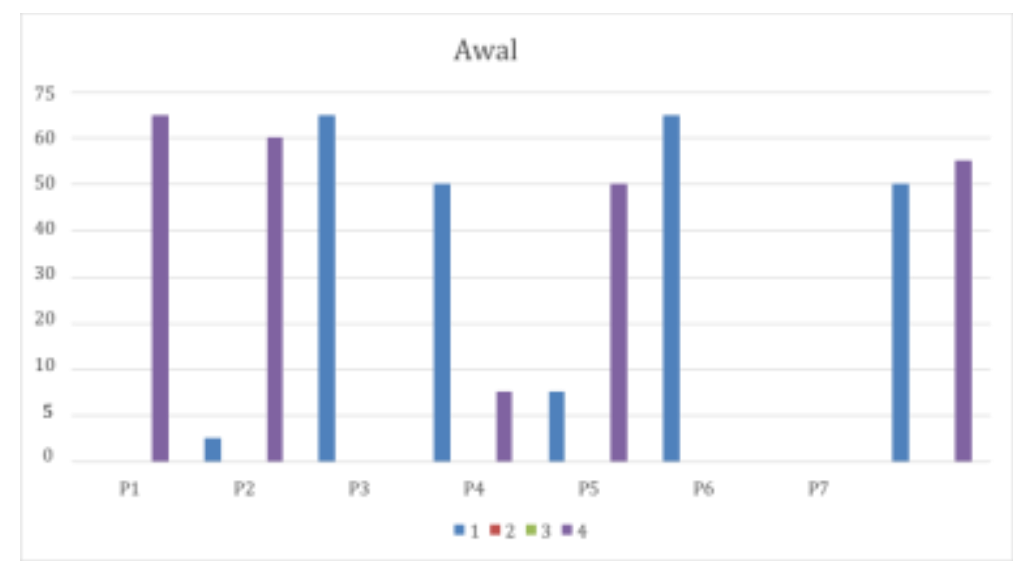

Gambar 2 Grafik Hasil Formulir Evalusai Awal

Pada gambar 2 bisa dilihat bahwa peserta belum banyak memiliki pemahaman tentang Google Classroom dan Pembelajaran Berbasis E-Learning. 
PKM Blended Learning dengan Google Classroom for Education bagi Guru SMA Sederajat di Kecamatan Tambusai Provinsi Riau | Budi Yanto, dkk

\section{Hasil Formulir Evaluasi Akhir}

Dalam formulir evaluasi akhir, didapati hasil tentang sejauh mana kemampuan peserta dalam menggunakan Google Classroom. Tabel 2 merupakan hasil dari formulir evaluasi:

Tabel 2 Formulir Evaluasi Akhir

\begin{tabular}{|c|c|c|c|c|c|c|c|c|c|}
\hline \multirow[t]{2}{*}{$\mathbf{N o}$} & \multirow[t]{2}{*}{ Parameter } & \multicolumn{4}{|c|}{$\begin{array}{l}\text { Skala } \\
\text { Penilaian }\end{array}$} & \multicolumn{4}{|c|}{ Persentase } \\
\hline & & $\mathbf{1}$ & 2 & 3 & 4 & 1 & 2 & 3 & 4 \\
\hline 1. & $\begin{array}{l}\text { Memahami Blended Learning dengan } \\
\text { Google Classroom }\end{array}$ & $\mathrm{O}$ & $\mathrm{O}$ & 8 & 4 & $0 \%$ & $0 \%$ & $66,7 \%$ & $33,3 \%$ \\
\hline 2 . & Menguasai pembuatan Akun Gmail & $\mathrm{O}$ & 0 & 70 & 5 & $0 \%$ & $0 \%$ & $86 \%$ & $24,3 \%$ \\
\hline$\overline{3}$ & $\begin{array}{l}\text { Menguasai membuat kelas di Google } \\
\text { Classrom }\end{array}$ & $\mathbf{O}$ & $\mathbf{O}$ & 40 & 35 & $0 \%$ & $0 \%$ & $58,3 \%$ & $48,7 \%$ \\
\hline 4. & $\begin{array}{l}\text { Menguasai mengundang guru pada } \\
\text { Google Classroom }\end{array}$ & $\mathbf{O}$ & $\mathbf{O}$ & 35 & 40 & $0 \%$ & $0 \%$ & $50 \%$ & $50 \%$ \\
\hline 5. & $\begin{array}{l}\text { Menguasai membuat pengumuman } \\
\text { dalam kelas yang telah dibuat }\end{array}$ & $\mathrm{O}$ & $\mathrm{O}$ & 5 & 70 & $0 \%$ & $0 \%$ & $16,7 \%$ & $83,3 \%$ \\
\hline 6. & $\begin{array}{l}\text { Menguasai upload materi pada } \\
\text { Google Classroom }\end{array}$ & $\mathbf{O}$ & $\mathbf{O}$ & 25 & 50 & $0 \%$ & $0 \%$ & $41,7 \%$ & $58,3 \%$ \\
\hline 7. & $\begin{array}{l}\text { Menguasai } \quad \text { tata kelola } \\
\text { pada Google }\end{array}$ & 0 & 0 & 70 & 5 & $0 \%$ & $0 \%$ & $75 \%$ & $25 \%$ \\
\hline 8. & $\begin{array}{l}\text { Menguasai menggunakan salah satu } \\
\text { aktifitas tugas pada Google Classroom }\end{array}$ & $\mathrm{O}$ & $\mathrm{O}$ & 45 & 30 & $0 \%$ & $0 \%$ & $50 \%$ & $50 \%$ \\
\hline 9. & $\begin{array}{l}\text { Menguasai mengoperasikan secara } \\
\text { keseluruhan Google Classroom }\end{array}$ & $\mathrm{O}$ & 0 & 72 & 3 & $0 \%$ & $0 \%$ & $66,7 \%$ & $33,3 \%$ \\
\hline Rat & rata & & & & & $0 \%$ & $0 \%$ & $47,3 \%$ & $52,7 \%$ \\
\hline
\end{tabular}

Pada tabel 2 berisi parameter mengenai kemampuan peserta dalam pemahaman dan pengoperasian Google Classroom setelah diadakannya pelatihan, dengan disertakannya hasil skala penilaian yang didapat dari 75 peserta yang mengisi Formulir Evaluasi Akhir.

75

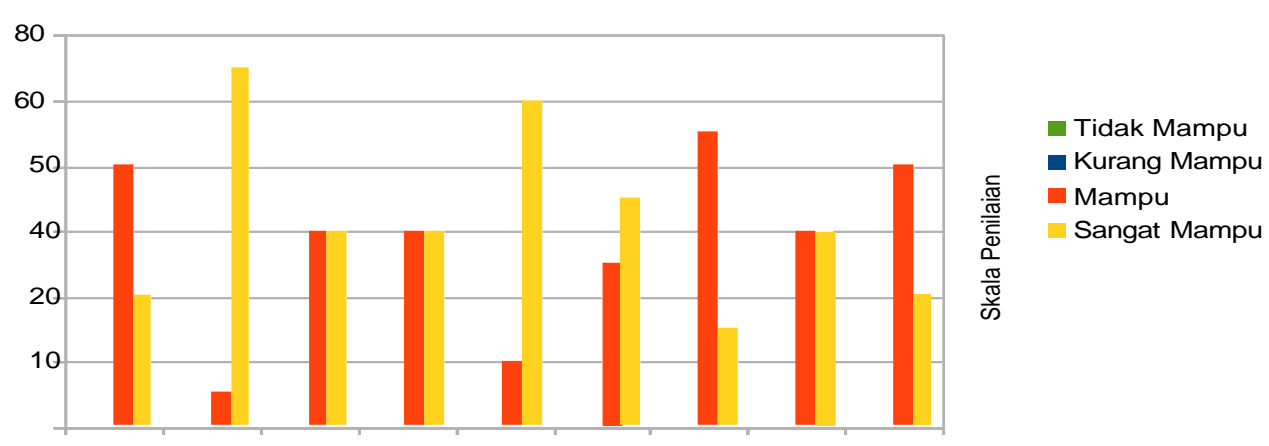

Gambar 3 Grafik Hasil Formulir Evaluasi Akhir

Gambar 3 menjelaskan bahwa setelah dilakukannya pelatihan terkait pemahaman dan pengoperasian Google Classroom dapat ditarik kesimpulan bahwa semua peserta mampu memahami dan mengoperasikan Google Classroom dan bahkan di 52,7\% peserta sudah sangat mampu dalam mengoperasikan Google Classroom. 
Pelatihan dan pendampingan dalam memanfaatkan google classroom sebagai media pembelajaran daring online yang bisa berjalan di smartphone, membuat kelas tanpa kertas (paperless) yang bisa diakses di mana saja, dengan syarat internet mesti terhubung. Materi diberikan dengan waktu 32 jam yang akan dilampirkan materinya pada sertifikat yang berguna untuk kenaikan pangkat bagi guru. Sertifikat diberikan sebagai bentuk penghargaan apresiasi atas antusiasnya peserta yang telah mengikuti pelatihan ini. Diharapakan semoga dengan pelatihan ini bisa berkelajutan dan difungsikan sebagaimana mestinya, di mana guru-guru sebagai peserta berharap diberikan pelatihan lagi untuk memperdalam lagi ilmu mereka dengan bahan dan modul teknologi informasi yang baru.

Berdasarkan kegiatan yang telah dilakukan dapat dijelaskan bahwa luaran yang dicapai adalah sebagai berikut:

1. Meningkatnya pemahaman dan kreatiftas peserta yaitu Guru SMA di kecamatan Tambusai dalam pemanfaatan google classroom for education, melalui PC dan melalui smartphone masing-masing peserta

2. Dihasilkan sebuah produk Modul google classroom for education sebagai bahan referensi

3. Dihasilkannya tutorial video dalam proses penyampain dan penggunaan google classroom for education

4. Draft untuk di submit pada jurnal publikasi dari hasil PKM

5. Publikasi hasil kegiatan pelaksanaan PKM melalui media online

\section{Penutup}

Berdasarkan hasil pelaksanaan PKM yang telah dilaksanakan sampai dengan dibuatnya laporan kemajuan ini dapat disimpulkan bahwa dengan dilaksanakan kegiatan PKM pemanfaatan google classroom sebagai media pembelajaran daring sangat berdampak positif bagi guru-guru dalam proses belajar mengajar di SMAN Kecamatan Tambusai, Kabupaten Rokan Hulu, Provinsi Riau. Untuk maksimalnya dalam pemanfaatan ini perlu kembali diadakan pelatihan kembali, bukan ke guru-guru saja tetapi untuk siswanya juga.

\section{Ucapan Terima Kasih}

Terima kasih kepada Menristekdikti yang telah memberikan dana hibah untuk biaya pelaksanaan penelitian ini, serta untuk Universitas Pasir Pengaraian yang juga telah memberi dukungan finansial.

\section{Daftar Pustaka}

Asnawi, N. (2018). "Pengukuran Usability Aplikasi Google Classroom Sebagai Elearning Menggunakan USE Questionnaire (Studi Kasus: Prodi Sistem Informasi UNIPMA)". Research : Journal of Computer, information system, \& technology management, 1 (2).

Hakim, A. B. (2016). "Efektifitas Penggunaan E-Learning Moodle, Google Classroom dan Edmodo". I-STATEMENT, 2 (1).

Pradana, D. B. (2017). "Pengaruh Penerapan Tools Google Classroom pada Model Pembelajaran Project Based Learning terhadap Hasil Belajar Siswa". Jurnal IT-Edu, Volume 02 (Nomor 01). 
PKM Blended Learning dengan Google Classroom for Education bagi Guru SMA Sederajat di Kecamatan Tambusai Provinsi Riau | Budi Yanto, dkk

Gunawan, F. I. (2018). "Pengembangan Kelas Virtual dengan Google Classroom dalam Keterampilan Pemecahan Masalah (Problem Solving) Topik Vektor Pada Siswa SMK untuk Mendukung Pembelajaran".

Wicaksono, V. D. ( 2017). "Pembelajaran Blended Learning Melalui Google Classroom di Sekolah Dasar”. Prosiding Seminar Nasional Pendidikan PGSD UMS \& HDPGSDI Wilayah Jawa. 